\title{
A Ética no Marketing
}

\section{André Cauduro D’Angelo}

\section{Resumo}

De todas as atividades empresariais, o marketing é a de maior visibilidade e, por isso, a mais sujeita a questionamentos de ordem ética. Historicamente, as práticas de marketing têm sido alvo de críticas, o que torna pertinente uma revisão da literatura acadêmica relativa ao tema e a análise das principais contribuições oriundas dos trabalhos publicados. Existem basicamente duas categorias de questionamentos éticos em relação ao marketing: a primeira, ligada às características do sistema capitalista, diz respeito ao presumível estímulo materialista despertado pelo marketing; a segunda, de caráter mais prático, enfoca atividades de marketing como precificação, propaganda e vendas. Em comum entre ambas está a multiplicidade de visões relativas à ética que, por se tratar de tema complexo e subjetivo, está sujeita a diferenças de interpretação, que variam conforme as circunstâncias e as percepções, dificultando o consenso. Como resultado, os atores do marketing e do mundo dos negócios tendem a se mover em certa zona de amoralidade, deixando que o mercado e a sociedade julguem as suas práticas.

Palavras-chaves: ética no marketing; questionamentos éticos; consumerismo; soberania do vendedor; soberania do consumidor.

\section{Abstract}

Marketing is probably the organizational function with more visibility and it is constantly being put under discussion from the ethics point of view. Marketing practices have been historically criticized, making the analysis of its ethical aspects an important and necessary topic in the academic environment. There are basically two categories of questions concerning marketing ethics: the first one is related to the capitalist system as a whole and discusses the supposed materialist stimulus developed by marketing; the second one has a more practical emphasis and is focused on marketing activities such as pricing, advertising and sales. Both of these categories are constituted of many points of views and there is no consensus about them; ethics is a complex and subjective concept and tends to be interpreted according to the circumstances and personal perceptions. As a result, marketing and business players move in an amoral zone, letting to the market and the society the task to judge them.

Key words: marketing ethics; ethics discussion; consumerism; seller sovereign; customer sovereign. 


\section{INTRODUÇÃO}

A discussão sobre a ética nos negócios - sinteticamente definida como o padrão de conduta e de moral vigentes no meio empresarial, permitindo a distinção entre o certo e o errado, o aceitável e o inaceitável (Gaski, 1999; Srour, 2000; Ferrell, Fraedrich e Ferrell, 2001) - tem sido recorrente entre acadêmicos e práticos de Administração há pelo menos quatro décadas. Embora o interesse pelo tema venha oscilando, obtendo maior ou menor destaque conforme as circunstâncias, a análise dos aspectos éticos nos quais as atividades empresariais estão envoltas já firmou posição como assunto relevante no meio acadêmico e empresarial. Na academia, o Journal of Business Ethics, publicação que já completou 20 anos, é o melhor exemplo do interesse dos estudiosos pelo tema. No meio empresarial, a emergência de códigos de ética nas organizações (Laczniak e Murphy, 1991; Fraedrich, 1996; Creyer, 1997; Wiley, 1997) e a criação de instituições que visam a estimular práticas mais éticas e socialmente responsáveis na iniciativa privada ilustram, igualmente, o fortalecimento desta tendência. Possivelmente os recentes acontecimentos no mercado norte-americano, assolado por diversas fraudes contábeis em algumas de suas principais empresas (Horta, 2002; Ramiro e Carvalho, 2002), impulsione um novo de ciclo de discussões acerca da ética nos negócios.

De todas as atividades empresariais, o marketing é, possivelmente, a mais sujeita a debates e questionamentos de natureza ética e moral (Nantel e Weeks, 1996; Lund, 2000; Singhapakdi et al., 1999a; Urdan e Zuñiga, 2001). Sua interface permanente com o mercado consumidor e o mercado empresarial confere visibilidade maior às suas práticas, colocando-as sob julgamento público permanente (Ferrel e Gresham, 1985; Lehmann, 1997; Smith, 2002). Não por acaso inúmeros códigos de ética procuram fornecer diretrizes a quem atua na área; alguns dos mais conhecidos são os da Associação Americana de Marketing (AMA), instituição que congrega profissionais e acadêmicos de marketing de todo o mundo, e, no Brasil, o do Conar (Conselho Nacional de Auto-Regulamentação Publicitária), que congrega anunciantes e profissionais de propaganda. Como característica principal, esses códigos apresentam diretrizes de comportamentos adequados às atividades de marketing, normatizando tais atividades e conscientizando seus profissionais acerca de seu papel social (O’Boyle e Dawson Jr., 1992). Fornecem, portanto, padrões éticos a serem perseguidos pelos profissionais, além de exibirem um caráter educativo e regulatório (O’Boyle e Dawson Jr., 1992).

Mesmo que nunca tenha despontado como o centro das discussões acadêmicas, 
a ética no marketing foi por muitas vezes abordada por estudiosos, ao longo da evolução da disciplina, como tópico relevante, fosse na tentativa de compreender a natureza da atividade, fosse na tentativa de oferecer modelos de análise que contemplassem a dimensão ética na tomada de decisão gerencial. Remontam às décadas de 60 e 70, principalmente, os debates concernentes ao impacto das ações de marketing na sociedade, bem como a sua aplicação a causas que não necessariamente teriam o lucro como objetivo final (marketing societal e social, respectivamente). Em décadas anteriores, já se havia assistido ao debate interminável acerca da validade ética e moral da propaganda, a face mais visível das atividades de marketing, conforme Greyser (1997). Embora não se possa afirmar que hoje este seja um tema de destaque na academia, observa-se que, com alguma freqüiência, é abordado em publicações como o Journal of Marketing e o European Journal of Marketing, além de, principalmente, Journal of Business Ethics, Journal of Macromarketing e Journal of Public Policy \& Marketing. Alimentam essas publicações acadêmicos respeitados que se têm dedicado a investigar, como linha permanente de pesquisa, os dilemas éticos que assaltam a disciplina e a prática de marketing, como bem mostram inúmeros trabalhos de O.C. Ferrell, Shelby Hunt, Larry Chonko, Gene Laczniac e outros.

Este artigo enfoca a ética no marketing sob três perspectivas. Na primeira, se oferece um panorama geral acerca das principais discussões do tema dentro da disciplina, procurando sintetizar seus elementos fundamentais. Na segunda, fazse uma análise da produção acadêmica atinente ao assunto, com ênfase especial nas recomendações providas pela academia aos profissionais de marketing e negócios e a abordagem de pesquisas referentes à ética do consumidor. $\mathrm{O}$ terceiro e último tópico contêm considerações finais sobre o tema e sugere algumas linhas de investigação para o Brasil.

\section{A Ética no Marketing: Breve Apanhado de Abordagens, Autores e Idéias}

Pode-se identificar, na crítica e no questionamento ético e moral ao sistema capitalista, a principal origem das discussões com as quais o marketing se vem defrontando desde o século passado. Os esteios éticos sobre os quais se fundamenta o capitalismo, desde os seus primórdios, vêm sofrendo forte contestação, que a emergência da sociedade de consumo do século passado só fez aumentar. Os trabalhos de críticos como John K. Galbraith e V. Packard (mencionados por Kotler [1972]), são dois dos mais notórios exemplos do questionamento e da contestação do sistema econômico e da sociedade que dele emergiu. Essas críti- 
cas ainda hoje reverberam nos meios intelectuais, produzindo análises que se filiam às mais diferentes correntes de pensamento e formação intelectual. Mesmo que as definições formais de marketing alarguem sua abrangência e significado e apontem uma dimensão histórica que remonta às atividades humanas mais longínquas (Bartels, 1988), moderna e popularmente o marketing é visto, na verdade, como instituição da sociedade de consumo, facilmente associada às atividades de venda e freqüentemente confundida com a propaganda pura e simples (Penteado Filho, 1990; Kotler e Armstrong, 1998). Se há muito a academia tratou ou tentou, pelo menos, dirimir quaisquer dúvidas quanto ao escopo e à natureza das atividades de marketing (ver, por exemplo, Kotler e Levy [1969], Kotler e Zaltman [1971], Bagozzi [1974, 1975]), o mesmo não se pode dizer das instituições que, presumivelmente, o aplicam diariamente, isto é, as empresas, principalmente onde ainda vigoram perspectivas antigas quanto aos reais objetivos da atividade ${ }^{(1)}$.

De qualquer forma, certo é que o marketing convive, há bastante tempo, com a crítica, a desconfiança e a dúvida quanto à validade ética e moral de seus princípios e práticas. Steiner (1976) apontou tais críticas, buscando raízes históricas ao que chamou de "preconceito contra o marketing". Segundo ele, das quatro utilidades fundamentais que uma mercadoria deve apresentar para satisfazer determinada necessidade humana - forma, tempo, lugar e posse - três pertencem ao escopo de marketing (tempo, lugar e posse), sendo as atividades profissionais a elas relacionadas as menos valorizadas desde há muito. Platão e Aristóteles, por exemplo, atacavam lojistas e comerciantes, definindo-os como "não-amigáveis e inconfiáveis". Outros pensadores de Atenas os definiam como "trapaceiros", "dissimulados" ou "parasitas". As atividades de venda e propaganda também teriam sofrido de preconceito semelhante desde a época "da Bíblia, de Confúcio e da literatura grega clássica”, conforme Star (1989, p. 148). Mais recentemente, Veblen e Galbraith (apud Steiner, 1976) teriam sido alguns dos inimigos da propaganda, definindo seus profissionais como "manipuladores". A propaganda, segundo Steiner (1976), foi apontada também como não-produtiva, visão da qual o fotógrafo Toscani (1996), célebre pelas provocativas campanhas da griffe Bennetton, compartilhou recentemente. Farmer (1967), quase dez anos antes, também identificava as acusações principais às quais o marketing estava submetido: falta de ética e irrelevância. O título de seu artigo não poderia ser mais sugestivo: Você gostaria que sua filha casasse com um homem de marketing?.

À semelhança do que foi mencionado na introdução deste artigo, é oportuno remeter-nos às próprias críticas históricas ao capitalismo para explicar tais discussões. É impossível não associar as práticas de marketing àquelas que são fundamentais para a condução de um negócio e, estas, àquelas que sustentam o sistema capitalista. Mesmo que a versão oficial dos defensores do sistema aponte 
que "os negócios prosperam ao atender às necessidades das pessoas", promovendo uma relação em que os benefícios são mútuos (Carrigan e Attalla, 2001), historicamente as relações entre empresas e clientes vêm apresentando um componente adversarial, em que os objetivos das duas partes nem sempre coincidem (Star, 1989; Smith, 1995; Greyser, 1997; Haeckel, 1997; Singhapakdi et al., 1999a). A distribuição de poder nesta relação, ademais, também já foi identificada como desigual, dado que aos consumidores freqüentemente faltam informações para realizar as decisões mais adequadas de compra e, assim, exercer seus direitos (Kotler, 1972). Pertenceria às empresas, dessa forma, a maior parcela de poder. A contrariedade com o suposto poder exercido pelas empresas constitui, possivelmente, a crítica mais ácida e recorrente às instituições do sistema capitalista. Às empresas e aos seus sistemas de marketing atribuiu-se e ainda se atribui a capacidade de estimular que os consumidores vislumbrassem na aquisição de produtos e serviços a principal forma de não só satisfazer suas necessidades práticas de posse e utilização, como também suas necessidades de fundo emocional e social (Camenisch, 1991). A satisfação dessas necessidades, ou a própria criação delas, seria estimulada pela propaganda e tomaria forma em produtos considerados supérfluos e dispensáveis; valendo-se de artimanhas capazes de persuadir consumidores e aproveitar suas fraquezas, as empresas diminuiriam a capacidade racional de julgamento dos consumidores e encontrariam, assim, as condições propícias para a venda (Patterson, 1966; Farmer, 1967; Kotler e Levy, 1969; Galbraith, 1972; Greyser, 1973; Star, 1989; Camenisch, 1991; Kotler e Armstrong, 1998; Fineman apud Carrigan e Attalla, 2001). Ao longo do tempo, o estímulo crescente ao consumo teria criado uma sociedade excessivamente apegada aos bens materiais e desprovida de limites éticos para a sua obtenção (Klein, 1996; Kotler e Armstrong, 1998; Muncy e Eastman, 1998), em que as pessoas consumiriam até aquilo que lhes pudesse ser prejudicial ou mesmo prejudicial à coletividade ${ }^{(2)}$ (Feldman, 1971; Kotler, 1972).

Independentemente da crítica ao sistema, o certo é que, cotidianamente, o mundo dos negócios põe à frente de seus atores uma série de decisões e dilemas de natureza ética (Chonko e Hunt, 1985; Ferrel e Gresham, 1985; Laczniak e Murphy, 1991; Kotler e Armstrong, 1998; Hoffman, Couch e Lamont, 1999). Estes não estão restritos às atividades de marketing tão somente e se manifestam em quase todas as ações tomadas pelas organizações e seus profissionais que exerçam impacto direto ou indireto sobre consumidores, empregados, sociedade e poder público, por exemplo. Compreensivelmente, são as interações diretas de empresa e consumidor as mais visíveis e as mais passíveis de julgamento. São estas também as que mais têm sido alvo de regulamentação e de monitoramento por parte da sociedade civil e do poder público (Nantel e Weeks, 1996), em tentativa de conferir mais equilíbrio à relação dos agentes. O consumerismo (consumerism), movimento de consumidores que emergiu nos Estados Unidos em meados da década de 60, 
é um dos exemplos da intenção de pôr fim ao caveat emptor, princípio que predominou ao longo de boa parte do século 20, segundo o qual cabe ao consumidor munir-se de informações e cuidados para tomar a decisão de compra, não recaindo sobre o ofertante responsabilidades maiores, além de atuar dentro dos limites da lei (Smith, 1995; Greyser, 1997).

Um exame de algumas das atividades típicas dos profissionais de marketing é suficiente para perceber a freqüência com que acabam por se deparar com decisões de natureza ética. Desde a concepção do produto - matérias primas necessárias, características, nível de desempenho etc., até sua efetiva comercialização, praticamente todas as atividades de um sistema de marketing podem ser interpretadas de acordo com uma visão positiva ou negativa quanto à sua correção ética. Se a definição genérica de ética, em síntese o discernimento do que é certo e do que é errado (Patterson, 1966; Bartels, 1967), é ponto pacífico, a interpretação do que constitui conduta ética na prática dos negócios é terreno fértil à subjetividade e a muitas interpretações (Robin e Reidenbach, 1987; Laczniak e Murphy, 1991; Stark, 1993; Kotler e Armstrong, 1998). Daí também a complexidade e a dificuldade da tomada de decisão dos profissionais de marketing. A percepção do profissional pode não coincidir com a dos consumidores, mesmo que esteja respaldada na lei, por exemplo; ou a pressão exercida pelas empresas ou por executivos de níveis superiores pode conduzir à adoção de práticas que, visivelmente, contrariam alguns dos padrões éticos vigentes na sociedade naquele momento (Bartels, 1967; Ferrel e Gresham, 1985).

\section{A Ética no Marketing: Tentativa de Síntese}

A partir deste rápido panorama a respeito do tema da ética no marketing, é proveitoso que se desenvolva algum tipo de classificação que facilite a compreensão dos principais componentes e fatores envolvidos nesta discussão. Distante de pretender fornecer a síntese definitiva acerca do assunto, a classificação constitui-se essencialmente em instrumento didático, muito útil para fins de uma primeira incursão no tema.

A consulta à parte da literatura disponível permite apontar duas grandes categorias de questionamentos éticos com os quais o marketing se defronta. A primeira, mais genérica, está intrinsecamente ligada às características do sistema capitalista e diz respeito ao presumível estímulo materialista despertado pelo marketing e por suas ferramentas principais, especialmente a propaganda. Viuse, anteriormente, uma síntese dos principais argumentos que o tornam possivelmente o maior e mais difícil desafio ético a ser enfrentado pelo marketing.

A segunda categoria de questionamentos éticos relaciona-se à prática de negócios mais especificamente, tomando feição antes pragmática. Trata-se dos pa- 
drões de conduta das empresas nas suas relações com o consumidor final e outros agentes econômicos. Fazem parte dessa categoria as atividades relacionadas à promoção de produtos e serviços, à sua precificação, à prestação de informações aos consumidores e ao atendimento deles, à concepção de produtos e ao seu lançamento, além de toda uma infinidade de atividades que caracterizam a rotina dos profissionais de marketing e do próprio consumidor no mercado.

Os Quadros 1 e 2 sintetizam as duas principais categorias de questionamentos éticos com os quais o marketing se defronta, exemplificando alguns de seus principais dilemas mediante perguntas. A elaboração dos quadros partiu de colocações apresentadas pelos autores citados, as quais foram acrescidas alguns tópicos originais. Optou-se por privilegiar questões de complexidade e controvérsia distintas.

\section{Quadro 1: Alguns dos Questionamentos Éticos Genéricos ao Sistema de Marketing}

\begin{tabular}{|c|}
\hline $\begin{array}{c}\text { O marketing cria desejos e necessidades ou simplesmente os satisfaz? Os desejos } \\
\text { e necessidades do consumidor são moldados aos interesses das empresas? }\end{array}$ \\
\hline O marketing contribui para um apego excessivo às posses materiais? \\
\hline O marketing se prevalece de fraquezas e dificuldades emocionais das \\
pessoas para comercializar produtos e serviços?
\end{tabular}

Fonte: elaborado a partir de Kotler (1972), Greyser (1973), Moyer e Hutt (1978), Nantel e Weeks (1996), Kotler e Armstrong (1998), Carrigan e Attalla (2001).

Observa-se que as questões colocadas refletem episódios em que o impacto das ações de marketing pode ocorrer em nível micro (nos consumidores individualmente) e macro (na sociedade, de maneira geral). Ambos os níveis têm sido alvo de preocupação da sociedade e dos órgãos reguladores.

Verificado o contexto em que o debate sobre ética no marketing se insere, e identificadas suas principais características e vertentes, é pertinente examinar, agora, como a academia tem lidado com o tema nas últimas décadas. O item a seguir enfoca este tópico. 


\section{Quadro 2: Alguns dos Questionamentos Éticos Quanto às Práticas de Marketing}

\begin{tabular}{|c|c|}
\hline Produto & $\begin{array}{l}\text { O produto pode causar algum dano ou prejuízo a quem o utiliza? } \\
\text { O consumo constante do produto, ao longo dos anos, pode causar algum efeito } \\
\text { negativo ao consumidor? } \\
\text {. As informações prestadas aos consumidores a respeito do produto são suficientes e } \\
\text { adequadas à decisão de compra? A empresa omite algum componente do produto } \\
\text { que possa causar prejuízos no curto ou longo prazo para o consumidor? } \\
\text {. O produto lançado tem sua obsolescência planejada, devendo sair de linha dentro de } \\
\text { alguns meses/anos e perder valor para quem o adquirir? } \\
\text {. O processo de fabricação do produto, em algum estágio, causa danos ao meio- } \\
\text { ambiente? } \\
\text { A embalagem, embora atraente aos olhos do consumidor, representa desperdício de } \\
\text { algum material? }\end{array}$ \\
\hline Comunicação & $\begin{array}{l}\text { A comunicação promete vantagens que o produto não pode oferecer? } \\
\text { A comunicação direcionada a crianças, incapazes de discernir qualidades e defeitos } \\
\text { de um produto, é prejudicial a elas e suas famílias? }\end{array}$ \\
\hline Preço & $\begin{array}{l}\text { Os pacotes de preço manipulam as percepções de valor dos consumidores? } \\
\text { Os preços de acessórios e peças de reposição são muito elevados em relação ao preço } \\
\text { do produto, tornando cara sua manutenção? } \\
\text { O preço de produtos essenciais (por exemplo, medicamentos) é excessivamente alto, } \\
\text { dificultando o acesso de uma parcela do mercado consumidor? }\end{array}$ \\
\hline Promoção & $\begin{array}{l}\text {. Os preços praticados na promoção estão realmente abaixo daqueles praticados } \\
\text { normalmente? }\end{array}$ \\
\hline Distribuição & . Existe abuso de poder na relação entre os integrantes do sistema de distribuição? \\
\hline Vendas & $\begin{array}{l}\text { Os consumidores sentem-se pressionados e constrangidos com a postura do } \\
\text { vendedor? } \\
\text { O vendedor omite alguma informação relevante a respeito do produto, ou exagera } \\
\text { suas virtudes? } \\
\text { O vendedor tenta empurrar produtos que não são os mais adequados ao } \\
\text { consumidor? } \\
\text { O vendedor superestima as necessidades do consumidor, oferecendo produtos mais } \\
\text { caros? }\end{array}$ \\
\hline Atendimento & $\begin{array}{l}\text { O processo para cancelamento da prestação de determinados serviços é complicado e } \\
\text { demorado, tornando o cliente refém da empresa? } \\
\text { O acesso aos serviços de atendimento para reclamações e consultas pós-venda é } \\
\text { difícil? }\end{array}$ \\
\hline $\begin{array}{c}\text { Marketing } \\
\text { Internacional }\end{array}$ & $\begin{array}{l}\text { É correto comercializar em países em desenvolvimento produtos que são vetados por } \\
\text { órgãos reguladores de nações desenvolvidas, valendo-se de menores restrições legais } \\
\text { desses países? }\end{array}$ \\
\hline
\end{tabular}

Fonte: elaborado a partir de Kotler (1972), Greyser (1973), Moyer e Hutt (1978), Smith (1995), Kotler e Armstrong (1998).

\section{A Ética no Marketing: a Contribuição da Academia}

Indo além da abordagem trazida nas páginas anteriores - questionamentos éticos aos quais o marketing está sujeito - é proveitoso examinar de que maneira os acadêmicos têm tratado estes questionamentos e de que forma têm contribuído para a evolução do tema na disciplina. 
O professor John F. Gaski realizou extensa investigação sobre o tema da ética no marketing, consultando inúmeros trabalhos publicados por seus pares da academia. Seu estudo, publicado em 1999 no Journal of Business Ethics, apontou quatro focos principais de análise pelos acadêmicos: a ética na perspectiva filosófica e a maneira como se manifesta no marketing; o caráter ético intrínseco das atividades de marketing; pesquisas sobre crenças e comportamentos de práticos e teóricos de marketing; e indicações de comportamentos éticos a serem adotados por profissionais de marketing. Permeando estas quatro categorias existe um conjunto de recomendações e prescrições sobre postura ética no marketing, direcionadas aos profissionais da área. Todas as indicações, segundo o autor, podem ser sintetizadas em dois princípios fundamentais: obediência à lei e tomada de decisão baseada no próprio interesse, desde que dentro da lei. Pertencem ao rol de recomendações "não comercializar produtos perigosos ou potencialmente danosos” e “não enganar o consumidor”, além de algumas indicações quanto à precificação de produtos e serviços, "não praticar preços predatórios” está entre elas. Ademais, há também alguns exemplos de prescrições essencialmente baseadas na lei: "não coaja membros do sistema de distribuição"; e na defesa dos próprios interesses dos profissionais e de suas empresas: "não menospreze competidores” e “disponibilize canais para reclamações de clientes”. Conclusão do autor: “o que tem sido apresentado como questões éticas no marketing são, na realidade, nada mais do que questões legais e econômicas” (Gaski, 1999, p. 330). Admitindo, entretanto, que o conceito de marketing prevê "a consecução dos próprios interesses através do atendimento dos interesses dos outros” e que a lei representa "o melhor consenso da sociedade” (Gaski, 1999, p. 330), pode não haver motivos para preocupação ou temor pelos resultados encontrados.

O resultado do trabalho de Gaski (1999) intriga e instiga. Sabe-se que a lei e os regulamentos constituem amparo para qualquer decisão que se pretenda fundamentada na ética, mas não são, necessariamente, exaustivos ou completos. Existem inúmeros episódios em que a obediência cega à lei não é suficiente para atender às exigências éticas de uma situação (Bartels, 1967). Por isso não deixa de chamar a atenção o fato de que, apesar da complexidade dos temas tratados (vide Quadros 1 e 2) e dos fatores envolvidos na tomada de decisão dos profissionais de marketing, tenham sido providas pela academia duas prescrições tão pouco originais.

Possivelmente esteja por trás das recomendações fornecidas pela academia uma espécie de confissão quanto às dificuldade que a matéria encerra. Nash (1981) e Stark (1993) lembram que, a despeito do destaque que o tema ética nos negócios tem assumido nos meios acadêmicos, aos executivos e gerentes pouca ou nenhuma assistência concreta foi prestada. Prescrições dotadas de caráter 
absoluto e definitivo tendem a desconsiderar as dificuldades que executivos enfrentam no dia-a-dia; muitas decisões, ao serem tomadas, não permitem distinguir claramente o que é certo ou o que é errado, enquanto outras, embora permitam visualizar de imediato qual o caminho mais correto, colidem diretamente com interesses pessoais e corporativos. Em ambiente repleto de pressões externas e internas, escolher um caminho não é fácil e, por isso, pretender que sejam seguidas recomendações definitivas de ética pouco contribui para a prática. O melhor, segundo os autores, é adotar uma visão mais moderada, em que se privilegie a conciliação de diversos interesses e necessidades.

Corroborando as ponderações de Nash (1981) e Stark (1993), outros trabalhos apontam que a ética é tema complexo e subjetivo, sujeito a diferenças de interpretação, que variam conforme as circunstâncias e as percepções pessoais dos envolvidos (Ferrel e Gresham, 1985; Nantel e Weeks, 1996; Lund, 2000). Nos negócios, a tentativa de estabelecer exatamente o que sejam comportamentos éticos tende a obter consenso apenas quando tratada em nível genérico e eminentemente abstrato, tornando-se mais contestada à medida que avança para o específico e para o prático (Laczniak e Murphy, 1991). Não por acaso já se verificou que profissionais de marketing e dos negócios apresentam visões diferentes sobre o que constituem comportamentos éticos e antiéticos, visões que variam entre seus pares (Ferrel e Gresham, 1985) e de acordo com as circunstâncias envolvidas (Hoffman, Couch e Lamont, 1999). Já se observaram, igualmente, visões divergentes entre profissionais de marketing e consumidores (Singhapakdi et al., 1999b) e entre executivos e outros segmentos sociais (Sturdivant e Cocanougher, 1973). A própria vertente filosófica apontada como predominante no marketing, o utilitarismo, em que os fins justificam os meios (Robin e Reidenbach, 1987; Nantel e Weeks, 1996), é vista por muitos como inapropriada para o momento atual experimentado pelas sociedades democráticas, merecendo ser substituída por uma vertente deontológica, em que os meios utilizados para atingimento dos fins são tão importantes quanto estes (Kotler, 1972).

A partir dessas considerações, pode-se ensaiar algumas explicações para os resultados encontrados por Gaski (1999). A especulação que a revisão da literatura mais incentiva é a de que possivelmente os acadêmicos que se puseram a analisar os dilemas éticos dos profissionais de marketing recorreram às indicações mais convencionais justamente por assumirem a dificuldade inerente às decisões gerenciais, ou simplesmente por terem dificuldade em acreditar que, fora dos regulamentos estabelecidos pela Associação Americana de Marketing (AMA) ou de quaisquer outros códigos de regulamentação, exista oportunidade de se incorrer em determinações mais incisivas que tenham, realmente, significado prático. Estimular-se-ia, assim, a visão de que os melhores tribunais para as 
ações das empresas, pelos quais os profissionais de marketing poderiam orientar suas ações, seriam o mercado e a sociedade. Os parâmetros para orientar as ações das companhias estariam expressos na legislação, nos códigos de conduta, nos movimentos de defesa do consumidor e na própria pressão da sociedade civil, via outros canais de manifestação (imprensa etc.). Às empresas caberia responder às reivindicações externas, muito mais do que se antecipar a elas.

Convém observar que foi justamente por meio de reivindicações da sociedade que as relações de consumo sofreram transformação significativa nos anos 60 e 70, quando grupos de pressão e órgãos governamentais conduziram a mudanças nos padrões de conduta das companhias, em um movimento chamado de consumerism (Feldman, 1971; Bloom e Greyser, 1981). Examinando a literatura da época, e mesmo trabalhos mais recentes, observa-se que, de fato, o consumerism e seus movimentos derivados estimularam a idéia de que a convergência de necessidades individuais dos consumidores, interesses societais e objetivos empresariais seria a tônica dos produtos comercializados a partir de então (Kotler, 1972). Nos anos 90 também se observou tendência semelhante, ensejando a própria cunhagem do termo consumidor ético (Strong, 1996). Entretanto, alguns estudos que até hoje procuraram investigar as questões éticas envolvidas no comportamento de compra dos consumidores, não demonstraram que estas questões sejam menos complexas ou desprovidas de menos particularidades do que quaisquer outras relacionadas ao tema. Dada a importância que a reciprocidade assume no marketing, ou seja, à academia e aos práticos é necessário conhecer tanto o lado dos vendedores quanto dos compradores, o comportamento ético dos consumidores emerge como uma das áreas de investigação mais promissoras dentro da pesquisa da ética no marketing. Cabe, agora, examiná-la, procurando extrair mais algumas contribuições para a discussão do tema.

\section{Um Tópico Emergente: o Consumidor Ético}

A crença de que consumidores e sociedade passariam a influenciar, de maneira crescente, a ética nas relações de consumo, ganhou impulso há mais de trinta anos e, até hoje, só tem sido reforçada (Nantel e Weeks, 1996). Nos últimos anos a academia tem tratado de investigar de maneira mais profunda as características assumidas pelas questões de natureza ética de parte do consumidor, procurando verificar as opiniões e os comportamentos predominantes.

As indicações de que os consumidores se tornariam mais exigentes quanto à ética nas práticas das empresas basearam-se principalmente na crença de que a disponibilidade de informações e o nível de conhecimento acerca dos direitos do consumidor, entre outros fatores, produziriam consumidores mais sofistica- 
dos (Webster, 1997; Carrigan e Attalla, 2001), dispostos a punir empresas de comportamentos antiéticos (Carrigan e Attalla, 2001) e, com o tempo, privilegiar aquelas que reconhecidamente adotavam práticas corretas.

Se alguns dos estudos produzidos não desmentem categoricamente esta previsão, pelo menos desencorajam expectativas de que o comportamento ético do consumidor estaria menos revestido de complexidade do que o comportamento dos gestores na tomada de decisão de marketing. Alguns trabalhos verificaram, por exemplo, que os consumidores aplicam critérios de julgamento ético conforme as circunstâncias, tendendo a reagir de maneira diferente, conforme a situação e os resultados produzidos (Vitell e Muncy, 1992; Rawwas, 1996). A cultura local também se mostrou componente importante no julgamento das ações das empresas, verificando-se tendências de comportamentos diversos em diferentes países (Singhapakdi et al., 1999a; Rawwas, 2001). No Brasil, estudo desenvolvido por Urdan e Zuñiga (2001) não apontou vínculo causal entre a importância atribuída pelos consumidores ao comportamento ético das empresas e a propensão deles a recompensá-lo, ou seja, os consumidores disseram considerar importante o comportamento ético das empresas, mas nem por isso estariam dispostos a escolher seus produtos e serviços com base neste critério. Resultado diferente obteve Creyer (1997), que verificou não só a importância atribuída às questões éticas, como também identificou predisposição dos consumidores a punir maus comportamentos e recompensar ações consideradas corretas.

Em estudos desta natureza, em que são abordadas informações concernentes ao comportamento do consumidor, abordagens qualitativas tendem a ser bastante profícuas. A possibilidade de promover um mergulho mais profundo nos componentes emocionais e racionais que conduzem a determinado comportamento, ajuda não só a obter respostas de algum questionamento central, mas também e principalmente a entender motivos e circunstâncias que concorrem para sua elaboração (Rossi e Hor-Meyll, 2001). Assim, aos resultados mencionados no parágrafo anterior, provenientes de estudos de natureza quantitativa, é interessante adicionar contribuições advindas de recente investigação eminentemente qualitativa.

Estudo exploratório de Carrigan e Attalla (2001) apontou que elementos de natureza ética não afetavam o comportamento de compra dos consumidores entrevistados. Embora se fizesse menção a casos amplamente divulgados pela imprensa de conduta empresarial eticamente discutível, não houve reação significativa, a ponto de os consumidores repudiarem os produtos de determinadas companhias. Os consumidores, pelo contrário, tendiam a discutir se as ações das empresas eram mesmo eticamente condenáveis, numa tentativa de justificar as práticas das companhias e avalizar as suas próprias escolhas. Para alguns, os conceitos de ética e responsabilidade social estreitavam-se numa atuação das empresas dentro dos limites da lei e das regras de mercado. 
Carrigan e Attalla (2001) observaram também que: (1) alguns consumidores não dispunham de informações suficientes a respeito da postura ética das companhias; e que (2) mesmo dispondo de informações, não conferiam maior importância às questões éticas envolvidas, sentindo-se incapazes de influenciá-las de alguma maneira; e (3) reagiam de maneira diferente a diferentes apelos éticos, mostrando-se mais sensibilizados ou críticos a respeito de algumas ações empresariais em detrimento de outras, tendendo a atribuir maior importância àquelas ações que, de alguma forma, os afetavam de maneira mais direta. Conclusão dos autores: os fatores que mais influenciavam o comportamento de compra eram os tradicionais - preço, valor, imagem da marca, estética, status etc., e o posicionamento de mercado, baseado em atributos éticos, deveria ser precedido de uma análise dos valores do target, pois "alguns consumidores simplesmente não se engajam em questões que não os afetam diretamente, ou pelas quais não sentem simpatia” (Carrigan e Attalla, 2001, p. 571), tornando inócuo um argumento de venda desta natureza. A síntese dos autores é que "muitos abusos éticos das empresas podem continuar a acontecer, sem que ocorra qualquer impacto negativo no comportamento de compra do consumidor" (Carrigan e Attalla, 2001, p. 571).

Em síntese, é razoável supor que, assim como muitos profissionais de marketing, alguns consumidores estejam se deparando com dilemas éticos no momento do consumo (interesses pessoais versus incentivo ao comportamento ético de uma empresa, por exemplo) e que eventuais predisposições a tornar a postura ética das empresas um fator determinante na escolha de produtos permanecem mais sólidas como peça de retórica do que confirmação prática. Se, por vezes, acusou-se o descompasso entre as exigências éticas da sociedade e dos consumidores em relação às ações das empresas e, por outras, notou-se uma distância entre as recomendações acadêmicas e as possibilidades da prática gerencial em relação ao tema, pode-se estar acompanhando também uma lacuna entre a expectativa da academia quanto ao comportamento ético do consumidor e seu efetivo desenvolvimento.

\section{Considerações Finais}

Após ter-se fornecido um breve panorama das discussões relativas à ética no marketing, é pertinente tecer algumas considerações finais acerca do tema e endereçar questões para futuras pesquisas.

Em artigo publicado na Folha de S. Paulo em maio de 2001, o filósofo José Arthur Gianotti escreveu que "os atores da política e da economia se movem 
num espaço de certa amoralidade” (Azevedo, 2002, p. 121). Isto não significaria necessariamente que fraudassem as regras estabelecidas, mas sim que "aproveitassem brechas legais para inaugurar o espaço da invenção” (Azevedo, 2002, p. 121), cabendo ao público julgá-los. O mundo dos negócios, e as práticas de marketing especialmente, parecem respeitar lógica semelhante. Às regras e regulamentos soma-se quantidade infinita de ações que transitam em espaço onde julgamentos de natureza ética e moral perdem objetividade e passam a ser efetuados sob o prisma das convenções pessoais, das práticas consagradas e das culturas locais. Se a inexistência de códigos de conduta, explícitos ou tácitos, representa convite às práticas nefastas, sua existência tampouco significa um ponto final à dubiedade inerente às questões de cunho ético. Nesse contexto, a experiência tende a conferir aos atores do mercado, isto é, empresas, profissionais e consumidores principalmente, a capacidade de desenvolver mecanismos que lhes garantam alguma proteção e preservação, permitindo sua sobrevivência; mas jamais o isentam do enfrentamento de dilemas e situações ambíguas. Como aponta Brennan (1991, p. 13), não se está sugerindo que as práticas dos negócios são "totalmente antiéticas [mas que] a linguagem dos negócios, os objetivos dos negócios e a maneira como os profissionais de negócios percebem seus papéis os colocam 'sob risco' de condutas antiéticas”.

Em consonância com essas observações, há outro aspecto interessante que merece ser abordado. A academia preconiza que as empresas devam estar voltadas para o consumidor, fazendo do atendimento de suas vontades e necessidades o principal motivo de sua existência (Webster, 1992, 1994, 2002). Nos últimos anos, tornou-se lugar comum advogar a soberania do consumidor (Sorell, 1994), estimulando a crença de que companhias que têm o consumidor em primeiro lugar apresentam melhores resultados. Pensamento semelhante parece ter norteado a defesa da soberania do consumidor também no que se refere ao julgamento ético das práticas das empresas. Numa hipotética passagem do caveat emptor (supremacia do vendedor) para o caveat venditor (supremacia do comprador), poder-se-ia assistir a uma elevação nos padrões éticos de consumo, em que as empresas de melhor conduta seriam premiadas com o melhor desempenho. Good ethics is good business, poder-se-ia proclamar (Brennan, 1991; Wiley, 1997).

Ainda assim, cumpre ver com reservas essas duas perspectivas. Como a soberania do consumidor no atendimento de seus desejos e vontades nem sempre é positiva para a empresa, pois há circunstâncias em que os interesses de ambos simplesmente colidem, o princípio do caveat venditor não é, tampouco, um indicador de que os consumidores sejam guardiões da ética e da moral. Agir conforme desejos e vontades do consumidor - e, por vezes, até da sociedade não significa, necessariamente, agir de maneira ética. “Às vezes, pode ser moral- 
mente caro dar ao consumidor o que ele quer", aponta Sorell (1994, p. 914). O que não significa, por outro lado, que o consumerism e outros movimentos de defesa de direitos do consumidor não constituam instituições fundamentais para a melhoria das relações entre os agentes do mundo dos negócios e do consumo. Em geral, esses movimentos complementam a atuação de órgãos reguladores do governo e das associações de classe, defendendo direitos consagrados. Deve-se apenas evitar incorrer no erro de que desequilibrar a balança para um dos lados, historicamente visto como vítima, lembra Sorell (1994), represente fazer justiça e se tornar imune aos erros e desvios próprios de qualquer processo de interação social.

Por fim, cabe registrar a pertinência da realização de estudos sobre a ética no marketing no Brasil. Uma consulta às principais publicações acadêmicas da área de Administração no país, no período de 1997 a 2001, apontou apenas um trabalho relacionado a este campo, o já citado estudo de Urdan e Zuñiga (2001). Em um país de particularidades socioeconômicas tão significativas, imerso em processo de pretensa modernização empresarial, há pelo menos uma década, estudos que procurem aprofundar a dimensão ética das práticas de marketing poderiam representar contribuição relevante no conhecimento em Administração do país. Seguem alguns tópicos que mereceriam investigação.

. Quais são os dilemas éticos que mais assaltam os profissionais de marketing do Brasil? Como os profissionais lidam com eles?

- Quais são os dilemas éticos dos profissionais responsáveis pelo marketing de organizações sem fins lucrativos ou de cunho social? Em que medida diferem, ou se assemelham, aos dilemas enfrentados pelos profissionais de companhias privadas?

- As percepções quanto a práticas éticas no marketing diferem de acordo com profissionais de diferentes setores? São diferentes das percepções dos consumidores?

- Qual é o nível de informação do consumidor a respeito das práticas das companhias e do seu impacto no indivíduo e na sociedade?

- O consumidor mostra-se propenso a boicotar empresas que não apresentem conduta adequada, ou a privilegiar produtos de companhias de postura reconhecidamente ética?

. As percepções de executivos e consumidores a respeito da ética no marketing guardam alguma relação com as raízes socioculturais do brasileiro?

Mesmo reconhecendo que investigações como as sugeridas acima guardem 
alguma complexidade, entende-se que a evolução das práticas empresariais no país e a relevância atribuída ao tema no cenário internacional representam incentivo a estudos nessa direção.

\section{Notas}

${ }^{1}$ Sobre isso, é emblemático o debate travado nas páginas da revista Exame, a principal publicação de negócios do Brasil, entre o professor de marketing Carlos A. V. Rossi e o executivo Clemente Nóbrega, sobre o que é marketing realmente. Ver também Webster (1992, 1994, 2002).

${ }^{2}$ Exemplo clássico de produto que causa prejuízos ao consumidor no longo prazo é o cigarro. Quanto a produtos que, de alguma forma, prejudicam a toda a sociedade, cita-se recorrentemente o exemplo dos automóveis (devido à poluição) e de todos aqueles produtos que têm como principal matéria prima elementos extraídos da natureza.

\section{ReferênCias Bibliográficas}

AMA.

American Marketing Association. Disponível em: <http:// www.marketingpower.com>. Acesso em: 10 dez. 2002.

AZEVEDO, R.

A máquina do mundo. Primeira Leitura, n. 5, jul. 2002.

BAGOZZI, R.

Marketing as an organized behavioral system of exchange. Journal of Marketing, v. 38, n. 4, Fall 1974.

Marketing as exchange. Journal of Marketing, v. 39, n. 4, Fall 1975.
BARTELS, R.

A model for ethics in marketing. Journal of Marketing, v. 31, Jan. 1967.

The history of marketing thought. Columbus: Publishing Horizons, 1988. cap. 1.

BLOOM, P. N.;

GREYSER. S. A.

The maturing of consumerism. Harvard Business Review, Nov./Dec. 1981.

BRENNAN, M.

Is there more to ethical marketing than marketing ethics? Marketing Bulletins, n. 2, 1991. 
CAMENISCH, P. F.

Marketing ethics: some dimensions of the challenge. Journal of Business Ethics, v. 10, n. 4, Apr. 1991.

CARRIGAN, M.;

ATTALLA, A.

The myth of the ethical consumer - do ethics matter in purchase behavior? Journal of Consumer Marketing, v. 18, n. 7, 2001.

CHONKO, L.;

HUNT, S. D.

Ethics and marketing management: an empirical examination. Journal of Business Research, Aug. 1985.

CONAR.

Conselho Nacional de Auto-Regulação Publicitária. Disponível em: <http://www.conar.com.br $>$. Acesso em: 10 dez. 2002.

CREYER, E.

The influence of firm behavior on purchase intention: do consumers really care about business ethics? Journal of Consumer Marketing, v. 14, n. 6, 1997.

FARMER, R. N.

Would you want your daughter to marry a marketing man? Journal of Marketing, v. 31, Jan. 1967.
FELDMAN, L. P.

Societal adaptation: a new challenge for marketing. Journal of Marketing, July 1971.

FERREL, O. C.;

FRAEDRICH, J.;

FERRELL, L.

Business ethics: ethical decision making and cases. [S.l.]: Houghton Mifflin College, 2001.

FERREL, O. C.;

GRESHAM, L. G.

A contingency framework for understanding ethical decision making in marketing. Journal of Marketing, Summer 1985.

FRAEDRICH, J. P.

Book review - do the right thing: ethics and marketing in a world gone wrong. Journal of Marketing, Jan. 1996.

GALBRAITH, J. K.

A sociedade afluente. Rio de Janeiro: Expressão e Cultura, 1972. cap. XI.

GASKI, J. F.

Does marketing ethics really have anything to say? A critical inventory of the literature. Journal of Business Ethics, v. 18, n. 3, Feb. 1999. 
GREYSER, S. A.

Public policy and the marketing practioner - toward bridging the gap. In: AllVine, F. C. Public policy and marketing practices. Chicago: AMA, 1973.

Janus and marketing: the past, present and prospective future of marketing. In: LEHMANN, D. R.; JOCZ, K. E. Reflections on the futures of marketing. Cambridge: MA-MSI, 1997.

HAECKEL, S.

Preface. In: LEHMANN, D. R.; JOCZ, K. E. Reflections on the futures of marketing. Cambridge, MA-MSI, 1997.

HOFFMAN, J. J.;

COUCH, G.;

LAMONT, B. T.

A teoria da relatividade ética. HSM Management, nov./dez. 1999.

HORTA, A. M.

O capitalismo bandido. Época, 15 jul. 2002.

KLEIN, T. A.

Book review - ethical decision making in marketing. Journal of Macromarketing, Spring 1996.

KOTLER, P.;

ARMSTRONG, G.

Princípios de marketing. 7.ed.
Rio de Janeiro: Prentice Hall, 1998.

KOTLER, P.;

LEVY, S.

Broadening the concept of marketing. Journal of Marketing, v. 33, Jan. 1969.

KOTLER, P.;

ZALTMAN, G.

Social marketing: an approach to planned social change. Journal of Marketing, v. 35, July 1971.

What consumerism means for marketers. Harvard Business Review, May/June 1972.

LACZNIAK, G.;

MURPHY, P.

Fostering ethical marketing decisions. Journal of Business Ethics, 1991.

LEHMANN, D. R.

Some thoughts on the futures of marketing. In: LEHMANN, D. R.; JOCZ, K. E. Reflections on the futures of marketing. Cambridge: MA- MSI, 1997.

LUND, D. B.

An empirical examination of marketing professional's ethical behavior in differing situations. Journal of Business Ethics, v. 24, n. 4, Apr. 2000. 
MOYER, R.;

HUTT, M.

Macromarketing. New York:

Wiley Hamilton, 1978. cap. 1.

MUNCY, J.;

EASTMAN, J. K.

Materialism and consumer ethics: an exploratory study. Journal of Business Ethics, v. 17, n. 2, Jan. 1998.

NANTEL, J.;

WEEKS, W. A.

Marketing ethics: is there more to it than the utilitarian approach? European Journal of Marketing, v. 30, n. 5, 1996.

NASH, L.

Ethics without the sermon. Harvard Business Review, Nov./Dec. 1981.

NÓBREGA, C.

Queremos você! Exame, 21 abr. 1999a.

Vamos estudar pessoal? Exame, 25 ago. 1999b.

O’BOYLE, E.;

DAWSON JR, L. E.

The American Marketing Association code of ethics: instructions for marketers. Journal of Business Ethics, v. 11, n. 12, Dec. 1992.
PATTERSON, J. M.

What are the social and ethical responsibilities of marketing executives? Journal of Marketing, v. 30, July 1966.

PENTEADO FILHO, J. R. W.

Marketing no Brasil: não é fácil. Rio de Janeiro: LTC, 1990.

RAMIRO, D.;

CARVALHO, A.

Um desencanto novo a cada dia.

Veja, 10 jul. 2002.

RAWWAS, M. Y. A.

Consumer ethics: an empirical investigation of the ethical beliefs of Austrian consumers. Journal of Business Ethics, v. 15, n. 9, Sept. 1996.

Culture, personality and morality - a tipology of international consumers' ethical beliefs. International Marketing Review, v. 18, n. 2, 2001.

ROBIN, D. P.;

REIDENBACH, R. E.

Social responsibility, ethics, and marketing strategy: closing the gap between concept and application. Journal of Marketing, v. 51, Jan. 1987.

ROSSI, C. A. V.

Arte ou ciência? Exame, 14 jul. 1999. 
ROSSI, C. A. V.;

HOR-MEYLL, L. F.

Explorando novas trilhas na pesquisa do consumidor. In: ENCONTRO ANUAL DA ANPAD, 25., 2001, Campinas. Anais... Campinas: ANPAD, 2001. 1 CD-ROM.

SINGHAPAKDI, A. et al.

A cross-cultural study of consumer perceptions about marketing ethics. Journal of Consumer Marketing, v. 16, n. 3, 1999a.

Ethics gap: comparing marketers with consumers on important determinant of ethical decisionmaking. Journal of Business Ethics, v. 21, n. 4, Oct. 1999b.

SMITH, N. C.

Marketing strategies for the ethics era. Sloan Management Review, Summer 1995.

Marketing social e contratos sociais - aplicando a teoria da integração dos contratos sociais às questões éticas do marketing social. In: ANDREASEN, A. R. (Org.). Ética e marketing social. São Paulo: Futura, 2002.

SORELL, T.

The customer is not always right. Journal of Business Ethics, v. 13, n. 11, Nov. 1994.
SROUR, R. H.

Ética empresarial: posturas responsáveis nos negócios, na política e nas relações pessoais. Rio de Janeiro: Campus, 2000.

STAR, S. H.

Marketing and its discontents. Harvard Business Review, Nov./Dec. 1989.

STARK, A.

What's the matter with business ethics? Harvard Business Review, May/June 1993.

STEINER, R. L.

The prejudice against marketing. Journal of Marketing, v. 40, July 1976.

STRONG, C.

Features contributing to the growth of ethical consumerism a preliminary investigation. Marketing Intelligence and Planning, v. 14, n. 5, 1996.

STURDIVANT, F. D.;

COCANOUGHER, A. B.

What are ethical marketing practices? Harvard Business Review, Nov./Dec. 1973.

TOSCANI, O.

A publicidade é um cadáver que nos sorri. Rio de Janeiro: Ediouro, 1996. 
URDAN, A. T.;

ZUÑIGA, K. H.

O consumidor recompensa o comportamento ético empresarial? In: ENCONTRO ANUAL DA ANPAD, 25., 2001, Campinas. Anais... Campinas: ANPAD, 2001. 1 CD-ROM.

VITELL, S.;

MUNCY, J.

Consumer ethics: an empirical investigation of factors influencing ethical judgments of the final consumer. Journal of Business Ethics, v. 11, n. 8, Aug. 1992.

WEBSTER, F. E.

The changing role of marketing in the corporation. Journal of Marketing, v. 56, n. 4, Oct. 1992.

Defining the new marketing concept.

Marketing

Management, v. 2, n. 4, 1994.

The future role of marketing in the organization. In: LEHMANN, D. R.; JOCZ, K. E. Reflections on the futures of marketing. Cambridge: MA-MSI, 1997.

Marketing management in changing times. Marketing Management, Jan./Feb. 2002.

WILEY, C.

O abc da ética empresarial. HSM Management, mar./abr. 1997. 